\title{
LA VALORACIÓN DEL RIESGO DE INUNDACIÓN EN LOS INSTRUMENTOS DE GOBERNANZA MUNICIPALES DEL SUR DE MURCIA
}

\author{
Alfredo Pérez Morales \\ Universidad de Murcia
}

\section{RESUMEN}

En los últimos treinta años, las inundaciones han causado la pérdida de un elevado número vidas y cuantiosos daños en España. Superada la etapa de las grandes obras de infraestructura como actuación principal para la mitigación del riesgo, la ordenación del territorio se presenta como medida racional, económica y sostenible, de reducción del peligro de las inundaciones en la escalas menores (regional, comarcal y, sobre todo, local). El trabajo valora la consideración que merece el peligro de inundaciones en los procesos de ordenación del territorio en la escala municipal y presenta algunas experiencias de interés.

\begin{abstract}
In the last thirty years, floods have caused the loss of a large number of people lives and extensive damage in Spain. Having passed the stage of large infrastructure projects such as acting principal for risk mitigation, regional planning is presented as a rational, economic and sustainable reduction in the risk of flooding on smaller scales (regional, district and especially, local). The work assesses the consideration it deserves the flood danger in the process of planning in the municipal level and presents some interesting experiences.
\end{abstract}




\section{INTRODUCCIÓN}

La búsqueda de seguridad frente a la posibilidad de inundaciones catastróficas se ha abordado tradicionalmente instalando infraestructuras de carácter defensivo, orientadas, con más o menos fortuna, a modificar los rasgos del fenómeno disminuyendo su peligrosidad o a dotar a los asentamientos humanos de solidez capaz de resistir la agresión.

Mediante las actuaciones señaladas en primer lugar, generalmente diseñadas teniendo presente no sólo la seguridad sino también el impulso al desarrollo económico de las poblaciones, se han creado, un poco por todas partes, numerosos espacios artificiales, cuya pervivencia depende directamente de la eficacia de las infraestructuras que los protegen; y ello pese a que hace ya tiempo, se ha llamado la atención sobre el hecho de que la instalación de infraestructuras cada vez más sofisticadas y complejas genera entre la población un sentimiento de falsa seguridad (BEYER, J.L.; 1974) que aumenta los efectos de una catástrofe si se superan los umbrales de seguridad establecidos.

Por otra parte, al tratarse de instalaciones costosas y que exigen tiempo para su implantación, tiende a demorarse ésta durante periodos a veces muy largos. Cuando los acontecimientos catastróficos se distancian en el tiempo, es posible considerar su repetición como algo remoto, y valorar como poco urgente acometer obras de gran envergadura, que detraen recursos económicos a cuestiones aparentemente más urgentes. Un buen ejemplo es el de las instalaciones de defensa en la cuenca del río Segura, que han tardado más de un siglo en completarse, desde que se diseñó el proyecto básico de los ingenieros GARCÍA y GAZTELU en 1887.

Desde hace aproximadamente tres décadas, este enfoque tradicional ha sido ampliamente criticado y complementado con otros puntos de vista, en particular por vincular las acciones de protección frente al fenómeno inundación con políticas de ordenación territorial que integren la posibilidad de que ocurra (OLCINA CANTOS, J.; 2007).

El análisis del riesgo natural en los documentos de ordenación del territorio es una herramienta de actuación legal, eficaz, racional y sostenible. Así empieza a ser entendido en Europa y España, merced a la aprobación de directrices, legislación del suelo y ordenación del territorio (de escala estatal y autonómica), que contemplan la obligación de incorporar análisis y cartografía de riesgos a la hora de plantear nuevos usos del suelo en un espacio geográfico.

En España, las comunidades son soberanas en materia de ordenación del territorio, de ámbito regional y subregional. La doctrina de la sentencia del Tribunal Constitucional de 20 de marzo de 1997 vino a reforzar este rasgo de la ordenación del territorio del Estado español, puesto que en ella se dictamina que el legislador estatal carece de toda competencia en materia de ordenación 
del territorio y urbanismo, por lo que ni siquiera puede promulgar normas con carácter supletorio en estas materias. Ello se ha plasmado en la promulgación de legislación específica sobre la materia por parte de las administraciones regionales durante los últimos veinte años.

Hay que señalar que la ordenación del territorio en nuestro país ha ido ligada desde siempre al urbanismo (FARINÓS DASÍ, J., y ROMERO GONZÁLES, J.; 2008), actividad esta última que tiene un carácter muchas veces concurrente con la primera, lo que ha dado lugar a conflictos de intereses desde los inicios de su aplicación y ha motivado uno de los principales problemas que dificultan el desarrollo de medidas para la mitigación del riesgo natural en los documentos de planificación.

En este sentido, la Constitución de 1978 (art.148.1,3. ${ }^{\circ}$ ) otorga las competencias en dichas ordenación del territorio y urbanismo a las comunidades autónomas. Sin embargo, los municipios pronto vieron una intromisión en sus intereses en dicha disposición, por lo que pronto consiguieron garantizar constitucionalmente su autonomía para la gestión del urbanismo de acuerdo a la ley de bases del régimen local de 2 de abril de 1985, que vino a precisar y detallar estas competencias. Además, las sentencias del Tribunal Constitucional de 11 y 22 de diciembre de 1988 y de 2 de abril de 1992 refuerzan el papel de los municipios en la ordenación de su territorio, puesto que en ellas se considera suprimida, por entenderla incompatible con el modelo de autonomía municipal cristalizado en la ley de bases de 1985, «toda potestad de suspender de las autoridades administrativas y gubernativas (salvo la que se confiere al Delegado del Gobierno en el artículo 67)».

Por ende, la ordenación territorial se convierte desde entonces en un instrumento que se dedica a la formulación de planes, normas o programas supralocales, que orientan y regulan de forma racional las actuaciones y procesos de asentamiento sobre el territorio, a fin de garantizar el desarrollo socioeconómico, la protección de la naturaleza y del patrimonio histórico y cultural. Las funciones del urbanismo, no menos importantes, son un conjunto de reglas técnicas jurídicas y extra-jurídicas que tienden a garantizar la ordenación presente y futura del espacio comprendido por una aglomeración urbana.

Existe por tanto, una escisión bien definida entre ordenación territorial, cuya competencia recae sobre las autonomías, y urbanismo, que sería responsabilidad de los ayuntamientos. De este modo, la regulación de los aspectos más sustanciales de la propiedad inmobiliaria, entre el que destaca el derecho o no de urbanizar, pasan a manos del planificador municipal. Se sobrentiende que desde entonces, es la escala local donde la tarea de hacer frente al riesgo de inundación adquiere un mayor protagonismo, pues es la responsabilidad de los consistorios la de permitir o no la ocupación de espacios sensibles de ser afectados por las inundaciones. 


\section{LA CONSIDERACIÓN DEL RIESGO DE INUNDACIÓN EN LA LEGISLACIÓN MUNICIPAL DE ORDENACIÓN URBANA}

Los planes generales de ordenación urbana son el instrumento clave empleado por los municipios para la plasmación de políticas del territorio dentro de sus límites geográficos. Bien entendida la redacción de un documento de este carácter, la actuación se convierte en una herramienta eficaz para la prevención de la peligrosidad natural.

Entre todas las figuras de ordenación y planificación de escala local, el Plan General Municipal de Ordenación (PGMO de ahora en adelante) y las Normas Subsidiarias son las principales herramientas que tiene el administrador municipal para ordenar usos en el territorio y, en relación con ello, para incorporar medidas que puedan contribuir a mitigar los riesgos inherentes a una localidad (OLCINA CANTOS, J. 2004).

La clasificación del suelo municipal ha sufrido variaciones desde su primera introducción por la ley del suelo estatal de 1956. En líneas generales, el espacio municipal se regula en función de tres tipos:

- Suelo urbano: ya es ciudad, ya forma parte de la trama urbana. Se regula exhaustivamente su uso (residencial, industrial, equipamientos públicos, etc.) al detalle: qué se puede edificar, la forma concreta de hacerlo, qué actividades se pueden desempeñar, conforme a qué normativa, régimen de licencias, etc.

- Suelo urbanizable: no es ciudad todavía, pero forma parte del futuro desarrollo de la misma. Son las bolsas de suelo a urbanizar. En este sentido es por donde se dirige el futuro de la ciudad. Es una parte fundamental del plan. A través del desarrollo de este suelo el ayuntamiento consigue fuertes sumas de dinero y una buena cantidad de suelo: equipamientos públicos, cesión del aprovechamiento urbanístico, licencias.

- Suelo no urbanizable: más allá de ser un resto de serie, se trata de zonas de especial protección amparadas por la legislación sectorial. La ordenación de los espacios afectados por riesgos de cualquier índole se incluyen en esta categoría. Para su regulación, los planes municipales analizados transcriben lo dispuesto en los artículos 9.1 a de la ley estatal de 1998 y art.65.1 de la ley regional 1/2001. En consecuencia, el planeamiento sectorial es el responsable de delimitar el espacio afectado por las inundaciones, aunque los municipios y los gobiernos regionales por medio de sus instrumentos de ordenación territorial. En la Región de Murcia, el principal documento de referencia en la actualidad para este cometido es el plan especial de Protección Civil ante inundaciones (INUNMUR) elaborado por el organismo de Protección Civil regional y homologado en 2007 por el estatal. 
Por ello, resulta interesante el análisis pormenorizado de estos documentos, a fin de evidenciar el grado de percepción del riesgo natural de los mismos y, por ende, la vulnerabilidad social de las poblaciones que se organizan a partir de ellos. En este sentido, vamos a centrarnos en cuatro municipios de la Región de Murcia que han resultado especialmente afectados por las inundaciones. En primer lugar, el municipio de Mazarrón, tristemente famoso por la avenida de octubre de 1989 que barrió el camping de Bolnuevo; en segundo, Águilas, municipio donde se ha producido una de las mayores transformaciones de su espacio y las riadas e inundaciones hacen acto de presencia con una frecuencia creciente por este motivo; tercero, Lorca, núcleo de población cuya historia viene íntimamente ligada a las riadas del río Guadalentín; y finalmente, Puerto Lumbreras, donde se produjo la avenida más mortífera ocasionada por el sistema hidrográfico de una rambla de la que se tienen registros en la Península Ibérica.

\subsection{Plan General de Ordenación Urbana de Mazarrón. Revisión-adaptación de 2006}

El planeamiento vigente en el municipio de Mazarrón es la revisión-adaptación del Plan General de Ordenación Urbana de 9 de mayo de 1991; sin embargo, vamos analizar la última revisión de 2006.

El citado documento constituye la propuesta que el municipio realiza para su correcta inserción en la ordenación del territorio de la Región de Murcia y en el nuevo contexto urbanístico y socioeconómico. Para ello se aspira a la consecución de un nuevo plan que gestione la urbanización y el crecimiento de la ciudad y que resuelva los procesos urbanísticos que han dejado huellas negativas sobre su territorio.

Se advierte la voluntad por subsanar los desajustes de carácter urbanístico cometidos en el pasado y, por ende, los que evidencian los episodios de lluvia intensa sobre el espacio construido. A tal fin, el legislador incluye en la memoria del plan un catálogo de problemas (entre los que se incluyen los riesgos de inundación) que obstaculizan la definición de las líneas básicas estructurantes de la ordenación futura del municipio. Por desgracia, como sucede de forma generalizada en los planes de los consistorios levantinos (GIMENEZ FERRER, J.M.; 2003), el análisis de dichos obstáculos peca de excesiva superficialidad, su estudio es de poco rigor y se obvian contenidos básicos para el conocimiento del territorio sobre el que se va a materializar el modelo de desarrollo. Esto es muy evidente en la parte dedicada al medio físico y, en concreto, a los riesgos de inundación. El tratamiento del riesgo natural es apenas considerado en unas breves líneas, donde se identifican 36 puntos sensibles de sufrir inundaciones que, posteriormente, se plasman sobre una cartografía a escala 1:25.000. Sobre el tratamiento y mitigación de los mismos no se hace mención alguna en el resto del documento. 
En este sentido, los espacios afectados por riesgos de cualquier índole se incluyen en la categoría de suelo no urbanizable dentro del PGMO y son regulados por lo dispuesto en los artículos 9.1 a de la ley estatal (la ley 6/1998 de 13 de noviembre, de régimen del suelo y valoraciones), art.65.1 del texto refundido de la ley del suelo de la Región de Murcia (ambos idénticos) y 22 de las directrices y plan de ordenación del litoral de la Región de Murcia. En consecuencia, las dos primeras disposiciones remiten la regulación de dichos espacios al planeamiento sectorial, en este caso, a la delimitación elaborada por el organismo de Protección Civil regional, mientras no exista otra realizada por el organismo de Cuenca.

El mapa adjunto es el producto final que el organismo de Protección Civil regional ha elaborado de acuerdo a los criterios de zonificación de espacios inundables establecidos por la directriz básica de Protección Civil ante el riesgo de inundaciones y la superposición de parte de los puntos vulnerables por el planeamiento de Mazarrón, anteriormente señalados. Las variables representadas de Protección Civil son: a) la superficie inundable para los periodos de retorno de 50, 100 y 500 años; y b) la clasificación de zonas inundables de acuerdo a dichos periodos y la altura de agua. Para el caso del municipio de Mazarrón se distinguen al menos cinco espacios afectados, a los que se le asignan las siguientes categorías:

Tabla 1. Clasificación de zonas afectadas por las inundaciones en el municipio de Mazarrón según los resultados obtenidos en la cartografía del plan especial de

Protección Civil ante inundaciones de la Región de Murcia.

\begin{tabular}{|c|c|c|c|}
\hline CLASIFICACIÓN & LUGAR & $\begin{array}{c}\text { POBLACIÓN POTENCIAL } \\
\text { AFECTADA }\end{array}$ & $\begin{array}{c}\text { RÍO/ } \\
\text { RAMBLA }\end{array}$ \\
\hline $\mathrm{A}$ & Vado en Mazarrón & 0 & Moreras \\
\hline $\mathrm{A}$ & Carretera & 20 & Moreras \\
\hline $\mathrm{A}$ & Carretera & 696 & Moreras \\
\hline $\mathrm{Al}$ & $\begin{array}{c}\text { Núcleo urbano de } \\
\text { Bolnuevo y el Castellar }\end{array}$ & 7500 & Moreras \\
\hline $\mathrm{Al}$ & $\begin{array}{c}\text { Núcleo urbano de } \\
\text { Mazarrón }\end{array}$ & & 20 \\
\hline
\end{tabular}

Fuente: Plan INUNMUR

Como resulta fácilmente perceptible en el señalado mapa, los puntos vulnerables no corresponden en su totalidad a los espacios que el organismo de Protección Civil indica como sensibles de sufrir daños por inundaciones. Am- 


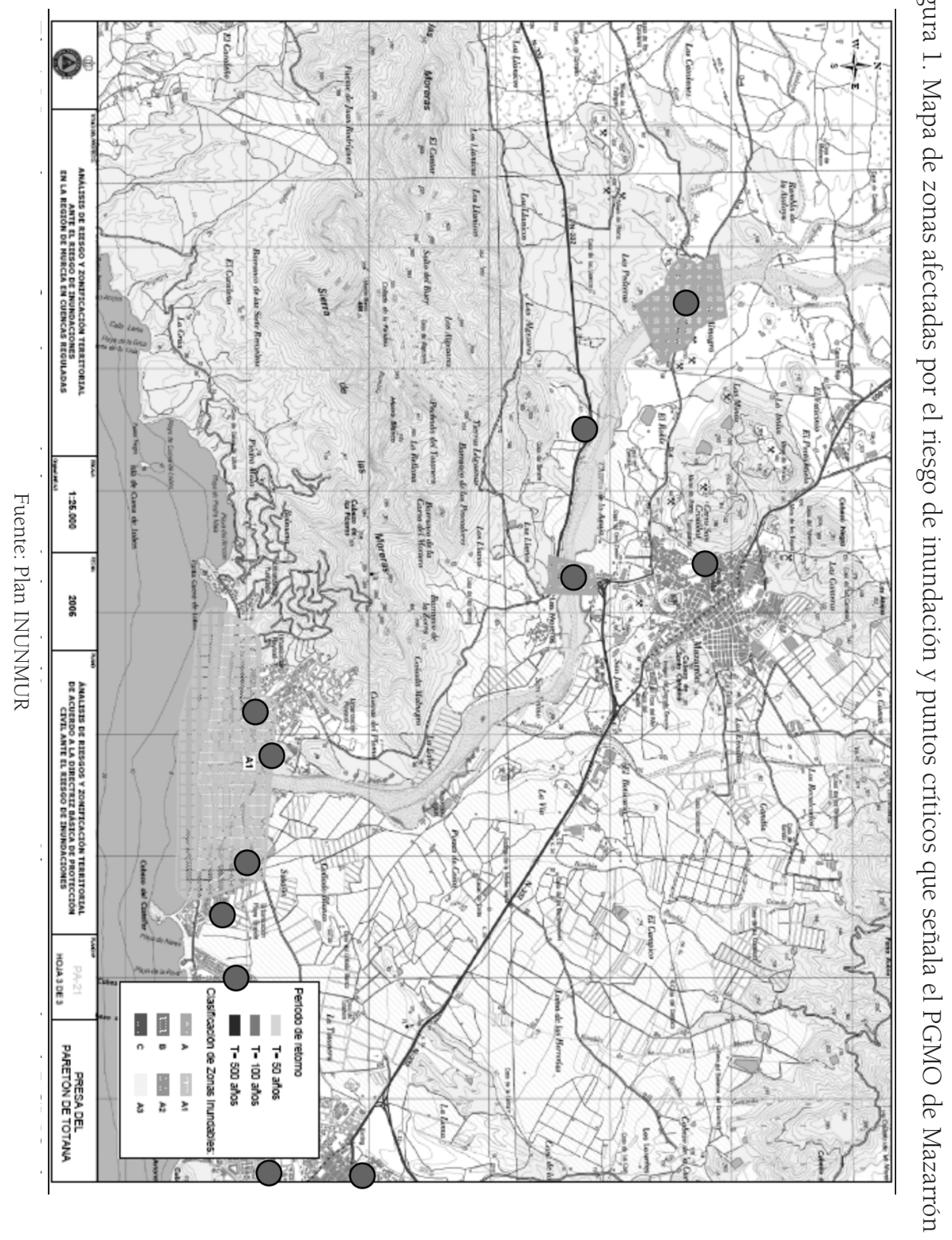


bas delimitaciones no guardan correlación en sus resultados, con lo cual, el responsable del proceso de asignación de usos del suelo se encuentra ante un primer desajuste en la cartografía de base para llevar a cabo la clasificación de usos.

El problema se complica aún más, ya que el municipio mazarronero se incluye dentro del espacio ordenado por las directrices anteriormente citadas y éstas, haciendo uso de sus competencias regionales en ordenación territorial, establecen mediante su art. 22 medidas de protección de cauces sin ningún tipo de criterio coherente con la realidad de los cauces naturales ni con la legislación del suelo estatal. La delimitación que propone consiste en una banda de 100 metros a ambos lados de los cauces, medida en los márgenes que se reflejan en la cartografía regional 1:5000. No se incluyen en esta categoría los suelos urbanos y urbanizables sectorizados que tengan dicha clasificación con la entrada en vigor de las directrices, con lo cual, la mitigación del riesgo que pueden ejercer encuentra sólo aplicación en el espacio urbanizable no sectorizado; el resto tan sólo se podrá proteger mediante medidas de carácter estructural. De este modo, la situación es de indefinición, y las medidas aplicables en este sentido se solapan y no se ajustan a la realidad.

En este mismo sentido, se advierte otra cuestión que puede motivar un incremento acentuado de la exposición. El PGMO reconoce que el municipio cuenta con elementos con las características con las que la Ley de Aguas (R.D.L. 1/01) determina el dominio público hidráulico (art.3.1.8 PGMO), es decir, los cauces. Sin embargo, el deslinde de los mismos está aún pendiente por parte del organismo competente, con lo cual, se deduce que el legislador debe adoptar como sustitutivo la delimitación propuesta por las DPOL (art.22). Desafortunadamente, dicha demarcación puede ser modificada de acuerdo a un estudio previo por parte del ayuntamiento interesado, y aprobado, en este caso, por el organismo competente en materia de ordenación del territorio y no por el de cauces, que sería el que por ley debería dar respuesta a dichos estudios. Estamos entonces ante un aspecto legal verdaderamente arbitrario que ofrece una gran discrecionalidad a la hora de modificar la delimitación del dominio público hidráulico, ya de por si artificial y a veces incoherente con la realidad.

De acuerdo a todo lo anterior, la nueva clasificación de usos del suelo que se propone desde el PGMO mazarronero apunta a un más que probable incremento de la exposición al peligro, sobre todo, si atendemos al crecimiento urbano estimado por el legislador municipal. En el siguiente cuadro se aprecian las cantidades de superficie aún por urbanizar: 
Tabla 2

\begin{tabular}{|c|c|c|c|c|}
\hline \multirow{2}{*}{$\begin{array}{c}\text { TIPO DE } \\
\text { SUELO }\end{array}$} & \multicolumn{4}{|c|}{ SUPERFICIE Has. } \\
\cline { 2 - 5 } & $\begin{array}{c}\text { NÚCLEO DE } \\
\text { MAZARRÓN }\end{array}$ & $\begin{array}{c}\text { PUERTO DE } \\
\text { MAZARRÓN }\end{array}$ & NÚCLEOS & TOTAL \\
\hline URBANO & 204.455 & 410.052 & 821.477 & $1.441,868$ \\
\hline NO & & & & $26.277,949$ \\
\hline URBANIZABLE & & & & $4.170,183$ \\
\hline URBANIZABLE & & & & \\
\hline
\end{tabular}

Fuente: Avance del Plan General de Ordenación Urbana de Mazarrón (2006)

De acuerdo a estas cifras, estarían pendientes de ejecutar en la categoría de urbano $64.611 \mathrm{~m}^{2}$ de suelo neto residencial, con una oferta potencial de 1.350 viviendas. En cuanto al suelo urbanizable, se calcula un suelo vacante de uso residencial (clasificado como urbanizable programado) de $2.300 .000 \mathrm{~m}^{2}$, con una oferta potencial de 4.600 viviendas, mientras que el no programado encuentra dificultades para su ejecución, pero es de destacar que, en el área de El Saladillo, se está construyendo una urbanización por parte de la empresa MASA, que hasta el momento lleva levantadas algo más de 6.000 viviendas, pero que proyecta unas 4.000 más.

Las aspiraciones por reconducir el modelo urbano hacia un proceso de ampliación que rentabilice al máximo su localización litoral se basan en el fomento del residencialismo como principal opción de desarrollo. Este hecho, en conjugación con la discrecionalidad evidenciada en materia de gestión y mitigación de riesgos en el documento de ordenación, hacen temer una nueva etapa que, lejos de corregir los problemas manifestados en este sentido durante estos años, parece que va a traducirse en un más que probable aumento de la exposición y la vulnerabilidad de la población y sus instalaciones. Llama entonces la atención la impasibilidad que demuestra el legislador municipal ante este tipo de eventualidades, cuando precisamente en este municipio, los daños producidos por los excesos de agua han sido dramáticos (basta recordar el desastre del camping de Bolnuevo), recientes, y lo que es más grave, frecuentes. Basta recordar la última inundación sufrida en octubre de 2009 en la urbanización Bahía localizada en el núcleo de Puerto de Mazarrón.

\subsection{Plan General de Ordenación Municipal del municipio de Águilas}

El municipio de Águilas cuenta con una superficie de 251,8 km², cuyos límites administrativos coinciden en su mayor parte con la divisoria de aguas que marca el arco de pronunciados relieves que rodea a este territorio. Consecuencia directa de la disposición orográfica mencionada, es la existencia de una densa red de ramblas que desembocan directamente al mar y que han sido integradas por el núcleo urbano. 
El documento de ordenación municipal de Águilas analiza en el apartado de su Memoria los aspectos estructurantes del municipio, entre los que se incluye el medio físico. Al igual que sucedía en el PGMO mazarronero, la parte que se dedica a esta cuestión es muy sintética y de escasa importancia con respecto a otras. Si bien, existe un apartado concreto que trata sobre los riesgos que afectan al municipio, aunque, para el de inundación, se limita a describir los factores que generan los chubascos de fuerte intensidad horaria responsables de las avenidas. No se aporta análisis de la hidrología del municipio, ni cartografía alguna que refleje el riesgo de inundación, por lo que se deduce que dicho párrafo es meramente descriptivo y no tiene significación alguna en el esquema de asignación de usos del suelo.

Para el planificador municipal, ese escueto estudio del marco físico es más que suficiente para la creación de un modelo territorial y de ordenación en el que se aspira como principal objetivo a incentivar los usos terciarios-turísticos como respuesta al desarrollo comarcal, en el contexto de las tendencias futuras del Arco Mediterráneo del siglo XXI (3.2 Memoria). Esa predisposición por promover la ocupación de espacios con fines turístico residenciales, a buen seguro generará tensiones con aquellos terrenos afectados por el riesgo de inundación, sobre todo si consideramos el margo legal que la ampara.

La clasificación de usos del suelo se efectúa de acuerdo a los artículos de las leyes del suelo estatal y regional por un lado, y las DPOL por otro. La intencionalidad de las mismas en materia de riesgos naturales, como ya se ha comprobado en el anterior apartado, no soluciona para nada los desajustes cometidos y, aún peor, no detiene los que se puedan producir en un horizonte próximo. Este hecho se percibe claramente, en los epígrafes del PGMO aguileño que hablan sobre la categorización del suelo no urbanizable. De acuerdo a la clasificación propuesta por la ley 1/2001, existen dos tipos: suelo de protección específica y el protegido por el planeamiento.

En cuanto al primero, el plan transcribe todos los supuestos que se incluyen en el art. 65.1 de la ley 1/2001 para su delimitación. En materia riesgos, el planificador municipal delega sobre el reglamento sectorial, en este caso, el plan INUNMUR.

Dicho estudio define una amplia zona del casco urbano de Águilas, que califica como inundable Al. Es decir, el área en la que la avenida de cincuenta años de periodo de retorno inundaría, afectando, en el caso de Águilas, a una población potencial de 2000 habitantes.

Junto a ellos, se consideran asimismo suelos no urbanizables de protección específica los determinados por las directrices y plan de ordenación territorial del litoral de la Región de Murcia. Como ya se señaló, en virtud del epígrafe 


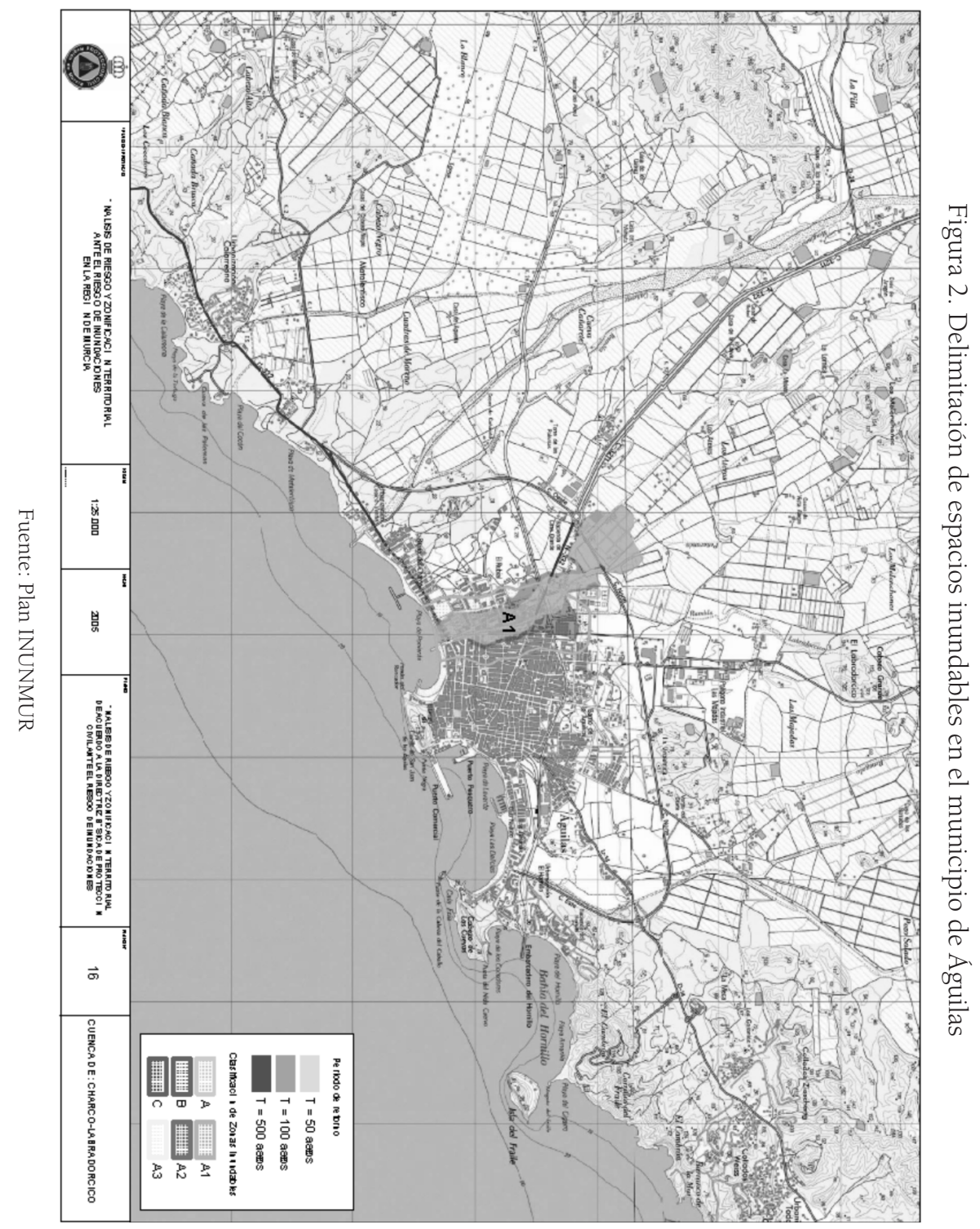


2.1.1.2 de dicho instrumento de ordenación, todas las ramblas que desaguan en el litoral murciano estarán sometidas a una banda de $100 \mathrm{~m}$ a ambos lados de los cauces, tomando como referencia los límites de los cauces reflejados en la cartografía regional 1:5000. Sin embargo, el trazado de dichos límites puede sufrir modificaciones arbitrarias en consonancia a lo que alude el Art. 11.

En consecuencia, la demarcación de Protección Civil y la de las DPOL se solapan en casos concretos, como la que se propone en la figura $\mathrm{n}^{\circ} 5$. Para el resto de cursos fluviales (al menos hay dos más que afectan directamente al casco urbano de Águilas), el único deslinde que prevalece es el del citado instrumento de ordenación territorial. Como bien es sabido, sus límites son totalmente discreccionales y no se ciñen para nada a la realidad del medio físico sobre el que se trazan. Con lo cual, existe un margen de terreno que queda desprotegido y pasa directamente a englobar los otros usos del suelo, pudiendo entonces ser aprovechado para su urbanización y, por tanto, aumentando la exposición al peligro.

Respecto al apartado del suelo no urbanizable que se viene comentando, el legislador municipal profundiza en cada uno de los supuestos que se incluyen en esta categoría para aclarar la aplicación del reglamento estatal sobre su término. Sin embargo, llama la atención que no se menciona en ningún momento la palabra riesgo entre los conceptos que el legislador distingue en este párrafo. Aunque ya queda claro anteriormente que este último es incluido como determinante en virtud del art. 65.1 de la ley 1/2001, es realmente inexplicable cómo se puede obviar un fenómeno de suma importancia, cuando los ejemplos de chubascos de fuerte intensidad horaria que han afectado al municipio son numerosos, significativos y recientes. Basta recordar como última fecha representativa la del 3 de mayo de 2006, cuando precipitaron más de $801 / \mathrm{m}^{2}$ en el intervalo de unas diez horas, provocando incluso la muerte de una persona que cruzaba una de esas ramblas.

Estos desajustes espaciales podrían ser medianamente solventados si el ayuntamiento incluyese aquellos espacios fuera del amparo de la protección específica en la otra categoría de suelo no urbanizable, es decir, el protegido por el planeamiento. No obstante, si recordamos el contenido de la memoria, la consideración del riesgo como factor determinante en la ordenación era mínima, por lo que es comprensible que en dicha categoría sólo se incluyan los siguientes supuestos: los terrenos caracterizados por su riqueza natural sus valores paisajísticos, y aquéllos reservados para la futura ejecución de infraestructuras y servicios previstos por el propio planeamiento. El concepto de riesgo, por tanto, no tiene cabida en este apartado legal; pese a ello, los cauces y zonas de servidumbre podrían ser integrados en el mismo, en función de su estado natural. Por desgracia, esto no deja de ser una medida dirigida a la protección de los valores ambientales. 
Sin perjuicio de lo anteriormente expuesto, el ayuntamiento de Águilas considera a ambas categorías de suelo no urbanizable parte activa del proceso de planeamiento y les asigna un uso complementario como sistema general, desde el momento en que se realice el deslinde administrativo del mismo. Este hecho genera cierta preocupación, pues cualquier aprovechamiento que suponga la transformación de estos espacios podría incurrir en un aumento repentino de la exposición al riesgo. De acuerdo con lo establecido en el art. 98 b) TRLSRM, los sistemas generales los constituyen los siguientes elementos: comunicaciones, servicios públicos, parques y jardines e instalaciones colectivas públicas.

La lectura de los usos que podrían acomodarse en espacios de protección específica es verdaderamente desalentadora. La permisividad para la ejecución de obras del calibre que se presentan demuestra una absoluta ignorancia por parte del legislador municipal en materia de riesgos de inundación. Resulta inaudito que instalaciones educativas, sanitarias, culturales, etc., puedan ocupar estas áreas sin el más mínimo impedimento. Afortunadamente, para la capital del municipio, el modelo de desarrollo pretende aprovechar el espacio de los cauces que la atraviesan mediante su transformación en grandes parques que constituyan ejes naturales que vertebren la ciudad. Es una opción adecuada y acorde al terreno que ocupan, sin embargo, la expansión del proceso urbanizador sobre otros espacios sensibles a los procesos de inundación podría ser empleada de forma incorrecta en virtud de dicho precepto.

Por otro lado, la presión urbanística sobre el suelo no urbanizable podría encontrar apoyo en los artículos 194 y 195 de la normativa urbanística del PGMO de Águilas. Ambos epígrafes recogen el régimen excepcional de edificación en suelo no urbanizable, tanto de protección específica como protegido por el planeamiento, respectivamente. El primero parece tener restringida cualquier tipo de construcción a expensas de lo que figure en el planeamiento específico de protección. En ausencia del mismo, como podría suceder con alguno de los lechos de inundación de las ramblas del litoral aguileño, la administración regional puede autorizar excepcionalmente alguna actuación, previo informe favorable del organismo competente en función del espacio en el que se instale. En teoría, el organismo de cuenca sería el responsable de determinar la conveniencia de dichas transformaciones si éstas se sitúan sobre espacios inundables. Pese a todo, no se entiende bien que en esta categoría de suelo, calificada como suelo incompatible con su transformación urbanística, se puedan permitir actuaciones, aunque se trate de edificaciones aisladas.

En cuanto al art. 196, es decir, el que habla sobre la excepcionalidad de edificación sobre el suelo que en teoría queda desprotegido, es el planeamiento municipal el que asume la responsabilidad. 
Las muestras de discrecionalidad y mala planificación que interceden sobre los espacios inundables son también evidentes en el apartado 3.4 de la normativa. En él se exponen los criterios para la delimitación de planes parciales sobre suelo urbanizable sin sectorizar. Éstos, en teoría, deberían establecerse de forma que se garantice su adecuada inserción en la estructura general establecida por el Plan y constituya una unidad geográfica y urbanística integrada. Sin embargo, dentro de dichos criterios, se baraja la posibilidad de incluir en los límites del plan parcial al suelo no urbanizable cuando concurran circunstancias excepcionales.

De acuerdo a lo anterior, ¿sobre quién recae la responsabilidad de insertar en un plan parcial un sector integrado en el espacio no urbanizable? Siendo éste un área de protección de cauces, ¿cómo se justifica su mejor adecuación al destino y función urbanística derivada del Plan? Las preguntas son numerosas e introducen incorrecciones que podrían facilitar la ocupación de espacios en riesgo.

Las carencias y discrecionalidades señaladas hasta ahora demandan una revisión urgente del documento de planificación del suelo aguileño. El buen funcionamiento del modelo de desarrollo propuesto depende en gran medida de la planificación que se haga del consumo de recursos físicos. En un entorno litoral, donde los condicionantes medioambientales han sido desde siempre un factor determinante en el desarrollo de las sociedades que se instalan, el riesgo de inundación debe representar un papel esencial en la dinámica del planeamiento.

Según las previsiones, el municipio de Águilas experimentará una de las transformaciones más importantes de todo el espacio ribereño mediterráneo con la ejecución de un macro complejo residencial en la Marina de Cope. Esta actuación y la propia expansión de la capital exigen sentar las bases estables de una planificación del territorio que otorgue a los condicionantes medioambientales un papel esencial. Para el caso concreto de los riegos de inundación, el estudio del medio físico debería dedicar un apartado exclusivo acompañado de cartografía específica al uso, que señale fielmente los desajustes existentes y proteja aquellos espacios del proceso urbanizador sin excepción alguna.

\subsection{Plan General de Ordenación Urbana de Lorca}

El Plan General de Ordenación Urbana del municipio de Lorca es el que regula la mayor superficie de la Región de Murcia. La ley estatal 6/1998 sobre el régimen del suelo y valoraciones y la 1/2001 del suelo de la Región de Murcia son los dos documentos en los que el ayuntamiento se basa para desarrollar la normativa de ordenación territorial y urbanística. Existe una revisión de dicho plan, pero aún sigue en proceso de evaluación por parte de la administración regional.

En desarrollo por lo establecido en las citadas leyes, el plan general se marca unos objetivos entre los que destaca, por íntima relación con los riesgos de inundación, 
la categorización y gestión de los distintos usos del suelo. A los efectos de establecer el régimen jurídico del suelo, el presente plan equipara sus determinaciones con los artículos 7 y siguientes de la ley 1/1998, art. 61 de la ley 1/2001para clasificar el suelo del término municipal en urbano, urbanizable, no urbanizable y sistemas generales.

En cuanto al no urbanizable, el PGOU de Lorca lo delimita siguiendo lo dispuesto en el artículo 9 de la ley estatal, y su trascripción en el 65 de la regional, como viene ocurriendo en todos los casos. Por lo tanto, merecen esta consideración aquellos espacios en los que "concurran riesgos naturales acreditados en el planeamiento sectorial» entre otros, es decir, lo que dispone en los resultados del plan INUNMUR.

Los mapas del plan INUNMUR adjuntos representan el entorno de la ciudad de Lorca y aguas abajo de la misma. Para el primero se distinguen tres categorías de riesgo de acuerdo a los criterios de la directriz básica contra inundaciones: I) A3. Recordemos que son aquellas zonas en las que la avenida de quinientos años produciría graves daños a núcleos urbanos. II) A. Son aquellas zonas en las que las avenidas de cincuenta, cien o quinientos años, producirán graves daños a núcleos de población importante. Son también aquéllas en las que las avenidas de cincuenta años producirían impactos en viviendas aisladas, o daños importantes a instalaciones comerciales o industriales y/o a los servicios básicos. III) C. Son aquéllas, no coincidentes con las zonas A ni con las zonas B, en las que la avenida de los quinientos años produciría impactos en viviendas aisladas, y las avenidas consideradas en los mapas de inundación, daños pequeños a instalaciones comerciales, industriales y/o servicios básicos.

Tabla 3. Clasificación de zonas afectadas por las inundaciones en el municipio de Lorca según los resultados obtenidos en la cartografía del plan especial de Protección Civil ante inundaciones de la Región de Murcia.

\begin{tabular}{|c|c|c|c|}
\hline CLASIFICACIÓN & LUGAR & $\begin{array}{c}\text { POBLACIÓN } \\
\text { POTENCIAL AFECTADA }\end{array}$ & RíO/RAMBLA \\
\hline A3 & Vado en Mazarrón & 9938 & Guadalentín \\
\hline A & Carretera & 120 & Guadalentín \\
\hline C & Carretera & - & Guadalentín \\
\hline
\end{tabular}

Fuente: Plan INUNMUR

El segundo de los mapas demuestra una de las carencias del citado plan de Protección Civil en el Valle del Guadalentín. Destaca, por encima de todo, que las ramblas afluentes que drenan los flancos orográficos septentrional y meridional no son abordadas en el estudio de inundabilidad. La razón no radica en que no exista riesgo alguno, pues varios episodios han dado buena muestra de 
Figuras 3 y 4 . Delimitación de zonas inundables en el municipio de Lorca

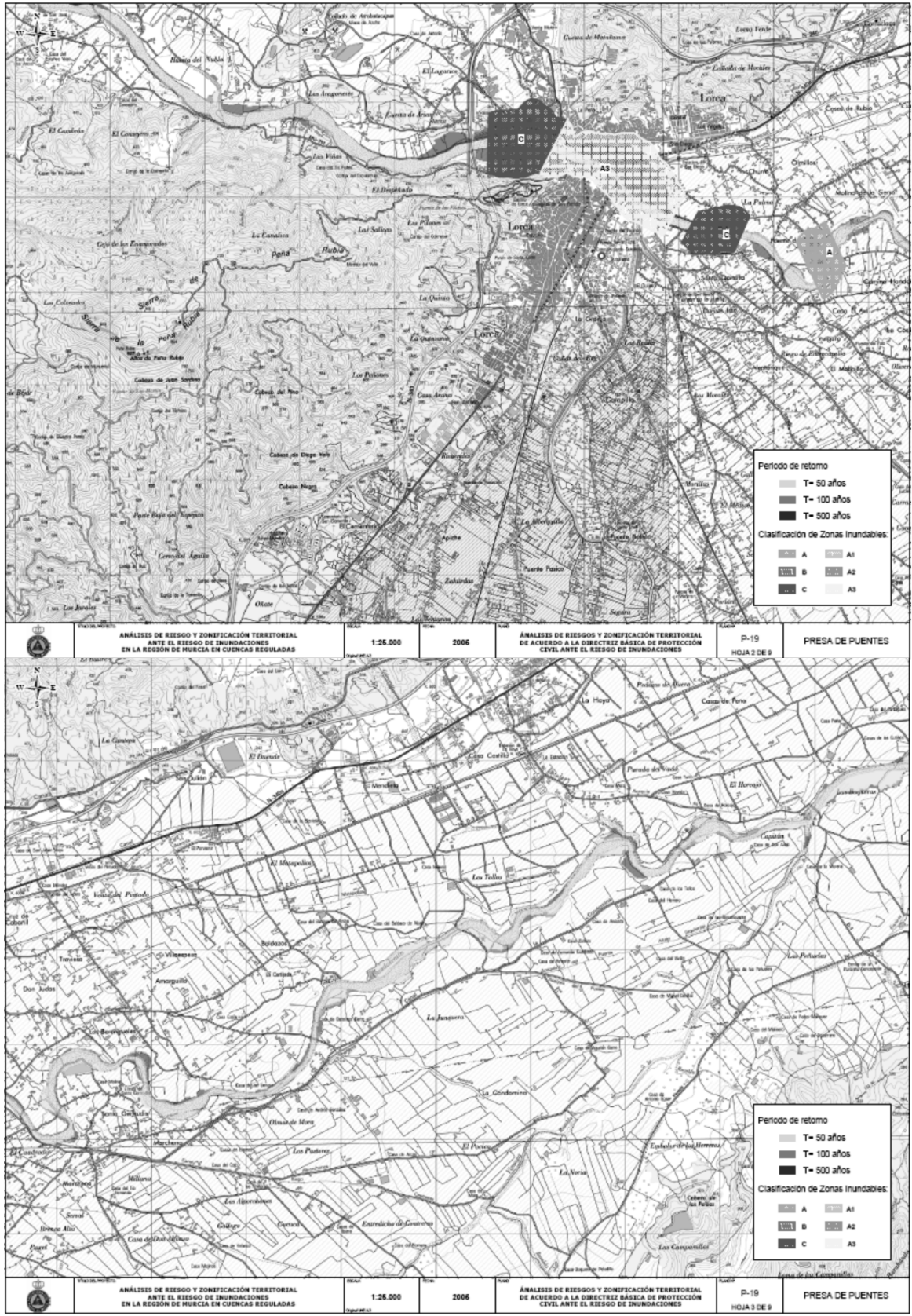

Fuente: Plan INUNMUR 
la exposición y vulnerabilidad de la población allí asentada. En el caso concreto de la pedanía de La Hoya, son dos ramblas (la Teja y Colmenar) las que alcanzan el piedemonte y afectan al núcleo poblacional. Este hecho se acentuó tras la construcción de la N-340 transversal al cauce de las mismas obstaculizando en gran medida la vía de desagüe natural, lo que provoca la inundación de espacios aledaños de forma recurrente. Al igual que aquí sucede, el resto de ramblas no encuentra cabida en el estudio, y por tanto, no se analiza el riesgo creciente que se está experimentando en dichos lugares. Éste es uno de los asuntos que el plan de Protección Civil debería solventar con urgencia, pues el régimen de asignación de usos depende totalmente de la fiabilidad de dicho documento. Cabe la posibilidad de que el plan de emergencia municipal que el organismo de Protección Civil regional debe homologar sí que las incluya.

En cuanto a la normativa del planeamiento de Lorca, dedica un apartado titulado «NORMAS GENERALES DE PROTECCIÓN» en el que se regula la protección que se hace de los espacios incluidos en la categoría de suelo no urbanizable, independientemente de la que se haga desde la legislación sectorial. Para los cauces públicos y sus márgenes (art.120) se delimita su espacio de acuerdo a lo establecido en la ley de aguas y el reglamento del dominio público hidráulico, es decir, exteriormente a la zona de servidumbre, se define la zona de policía, delimitada por una línea paralela al cauce distante a él 100 m. En teoría, en este espacio sólo serán permitidas las actuaciones que el reglamento de aguas estipule y siempre previa autorización de la Confederación Hidrográfica del Segura. Según la normativa urbanística, las edificaciones ordinarias deberán hacerse fuera de la línea que fija el límite de la avenida de 100 años de periodo de retorno.

Para establecer ambas demarcaciones administrativas, el planeamiento se autorresponsabiliza de incluir la delimitación del dominio público hidráulico y de sus correspondientes zonas de servidumbre y policía, pero para la que fijan los periodos de recurrencia, el legislador considera que deben encargarse los agentes privados que tengan interés en construir en espacios próximos a cauces. Asimismo, estos últimos deben incluir un estudio de las delimitaciones antes señaladas. Para ello, el legislador menciona que en el planeamiento se indica la documentación necesaria para poder informar sobre las futuras actuaciones urbanísticas que se encuentren en las zonas de influencia de los cauces públicos. Por desgracia, todo queda en papel mojado, pues se supone que la documentación necesaria para realizar ese tipo de estudio debería figurar en anexo II.1, y cuando acudimos a él, observamos un vacío que se interpreta, según fuentes directas a la redacción del plan, como un error del mismo.

Pese al buen espíritu de esta doble protección del espacio afecto a cauces, se advierten dos desajustes importantes que desfiguran la aplicación y funcionali- 
dad de la misma. Por un lado, que se permitan edificaciones más allá del límite que fija la avenida de 100 años de periodo de retorno quiere decir que las edificaciones sobre espacios inundables incluidos en la de 500 estarían permitidas. Este párrafo genera gran confusión, pues se supone que dicho margen espacial se encuentra protegido por el planeamiento sectorial, el de Protección Civil, con lo cual, la contradicción es evidente. Por otro lado, en el supuesto que existiese la documentación para que los mencionados agentes privados realicen estudios de inundabilidad, ¿cuáles serían las zonas de influencia de los cauces públicos que merecen ser estudiadas? ¿Quién debería aprobar dichos estudios? La interpretación que se hace de la normativa es que el límite de la avenida de 100 años de periodo de retorno marca la frontera a partir de la cual la edificación está permitida a expensas de los resultados del susodicho estudio de inundabilidad y de las excepciones que se hacen en el planeamiento para la construcción sobre suelo no urbanizable, pues en teoría, el margen entre el la avenida de los 100 años y la de 500 también está incluida en la categoría de suelo no urbanizable de protección específica.

El plan de ordenación incluye una relación de usos permitidos en suelo no urbanizable. Sin especificar la clase del mismo (de protección específica o de protección por el planeamiento), por lo que se entiende que en ambos es lícito, el plan incluye un listado en el que figuran usos coherentes como: actividades de conservación y regeneración de la naturaleza, esparcimiento y ocio, actividades agropecuarias, actividades forestales... pero resultan incomprensibles otros como: viviendas unifamiliares asociadas a la explotación (tanto las de nueva construcción como las rehabilitaciones), alojamientos rurales (hospederías rurales y casas rurales de alquiler) y campings. Con este amparo legal, la exposición al riesgo podría aumentar considerablemente, pues si tenemos en cuenta que la delimitación de espacios inundables propuesta falla por falta de rigurosidad y aplicación, es probable que las actuaciones permitidas puedan ocupar zonas sensibles de sufrir inundaciones.

Asignados los usos del suelo, los ayuntamientos disponen de otra herramienta para el control de la instalación de usos residenciales: la tramitación y expedición de licencias municipales. En el caso lorquino, este control previo se articula a partir de la imposición de un deber general de solicitar de la administración municipal autorización o licencia para cualquier acto de edificación recogido en el art. 221.3 de la ley 1/2001 del suelo de la Región de Murcia. Por desgracia, para la expedición del certificado acreditativo no se recogen más criterios que el hecho de que los proyectos presentados cumplan los requisitos de parcelamiento y edificación señalados en el plan. Con lo cual, no existe alusión alguna al entorno donde se vaya a situar esa nueva actuación que sea vinculante en esta decisión. 
La aplicación de la ley con los defectos advertidos está favoreciendo un nuevo aumento de los procesos de riesgos de inundación en el municipio lorquino (PÉREZ MORALES, A.; 2008). Se intuye una reducida preocupación en este sentido por parte de los responsables en la organización municipal, lo que resulta verdaderamente preocupante, pues la población no ha cesado de crecer en número a lo largo de este último siglo, y las previsiones de futuro son bastante generosas. La percepción del riesgo de inundación se está obviando con el paso del tiempo, y ello se traduce en una mala organización materializada en este documento de planeamiento urbano.

\subsection{Plan General de Ordenación Urbana de Puerto Lumbreras}

Puerto Lumbreras es el municipio con la menor superficie ordenable de los que se incluyen en el área de estudio. Pese a ello, el análisis pormenorizado de su correspondiente documento de planificación resulta verdaderamente interesante, pues, dentro de sus límites, se incluye casi íntegramente la cuenca de la rambla de Nogalte, tristemente famosa por ser la responsable del mayor desastre en número de víctimas del siglo XX en la Región de Murcia.

El Plan General Municipal de Ordenación de Puerto Lumbreras, aprobado en septiembre de 2007, se redacta con arreglo a las determinaciones establecidas en la ley 1/2001, de 24 de abril, del suelo de la Región de Murcia; y tanto en la ley $2 / 2002$, de 10 de mayo, como en la ley 2/2004, de 24 de mayo, ambas modificativas de la anterior.

Las determinaciones del plan reguladas por la legislación estatal se ajustan a lo establecido en la ley 6/1998, de 13 de abril, sobre régimen del suelo y valoraciones; en el real decreto ley 4/2000, de 23 de junio, de medidas urgentes de Liberalización, en los aspectos que modifica a la anterior, y; en los artículos vigentes del texto refundido de la ley sobre régimen del suelo y ordenación urbana, aprobado por real decreto legislativo 1/1992, de 26 de junio, declarados vigentes en la disposición derogatoria de la vigente.

De acuerdo a lo anterior, los aspectos más controvertidos que se vienen señalando en cuestiones de riesgo de inundación muestran en el plan de Puerto Lumbreras las mismas carencias que los municipios vecinos; sin embargo, son varias las iniciativas municipales encaminadas a la mitigación del riesgo que resulta interesante comentar a continuación.

Entre los criterios que el plan establece para ejecutar las tareas de gestión urbanística y ordenación, destacan por su interés con respecto a los riesgos de inundación los de de preservación del territorio y de protección medioambiental. Según el apartado a) del punto 7.1 de la ley, la protección medioambiental es uno de los pilares básicos de la política territorial, que tiene, 
entre otros, los objetivos de hacer compatibles y complementarios el desarrollo y la conservación de los recursos vivos, en este caso dentro del término de Puerto Lumbreras. Con esta premisa, el plan realiza la delimitación de los espacios que configuran el territorio en función de su valor natural o productivo, asignando a cada uno un tipo de uso. Por lo que se sobreentiende que los riesgos de inundación deberían tener un papel primordial dentro de dicho proceso.

La clasificación y división en categorías del suelo no urbanizable se ha realizado según las determinaciones de la ley 1/2001 regional, diferenciando:

- Suelo no urbanizable de protección específica.

- Suelo no urbanizable de protección por el planeamiento.

- Suelo no urbanizable inadecuado.

En lo que se refiere al suelo urbanizable de protección especifica (que es el que incluye los espacios en riesgo), el PGMO de Puerto Lumbreras transcribe lo dispuesto en los artículos 9 de la ley estatal, y el 65 de la regional, es decir, para que un espacio susceptible de ser inundado por las aguas de avenida sea considerado como no urbanizable, el planeamiento sectorial ha de incluirlo en su delimitación, en este caso, propuesta en el plan INUNMUR.

Como puede observarse en el mapa de delimitación de zonas inundables de Puerto Lumbreras presentado por Protección Civil, una parte importante del núcleo urbano aparece incluida en la zona Al. De acuerdo a los criterios establecidos en el citado plan de prevención, se trata de un área en la que la avenida de cincuenta años de periodo de retorno alcanza o supera los $30 \mathrm{~cm}$ de altura de lámina de agua que, en el caso de Puerto Lumbreras, afectaría a una población potencial de 1500 habitantes.

Esta delimitación es aprovechada por el legislador municipal, que delega cualquier responsabilidad en lo referente a la zonificación de espacios sensibles de ser afectados por las avenidas e inundaciones. Sobre todo si tenemos en cuenta que por parte del organismo de cuenca figura una alegación de carácter positivo hacia el plan. La Confederación Hidrográfica del Segura comunica al Ayuntamiento de Puerto Lumbreras que aunque no existe una delimitación del dominio público hidráulico ni de las líneas de avenida de 100 y 500 años en dicho documento, que es básicamente la misma que propone Protección Civil, no pone impedimento para la aprobación del citado documento, siempre y cuando los instrumentos de urbanización urbanísticos que lo desarrollen se sometan a informe de esta confederación hidrográfica y que el plan general explicite que dichos instrumentos se ajustarán a las limitaciones y condiciones que exprese dicho informe, resultantes de la protección del dominio público hidráulico y del régimen de corrientes. 


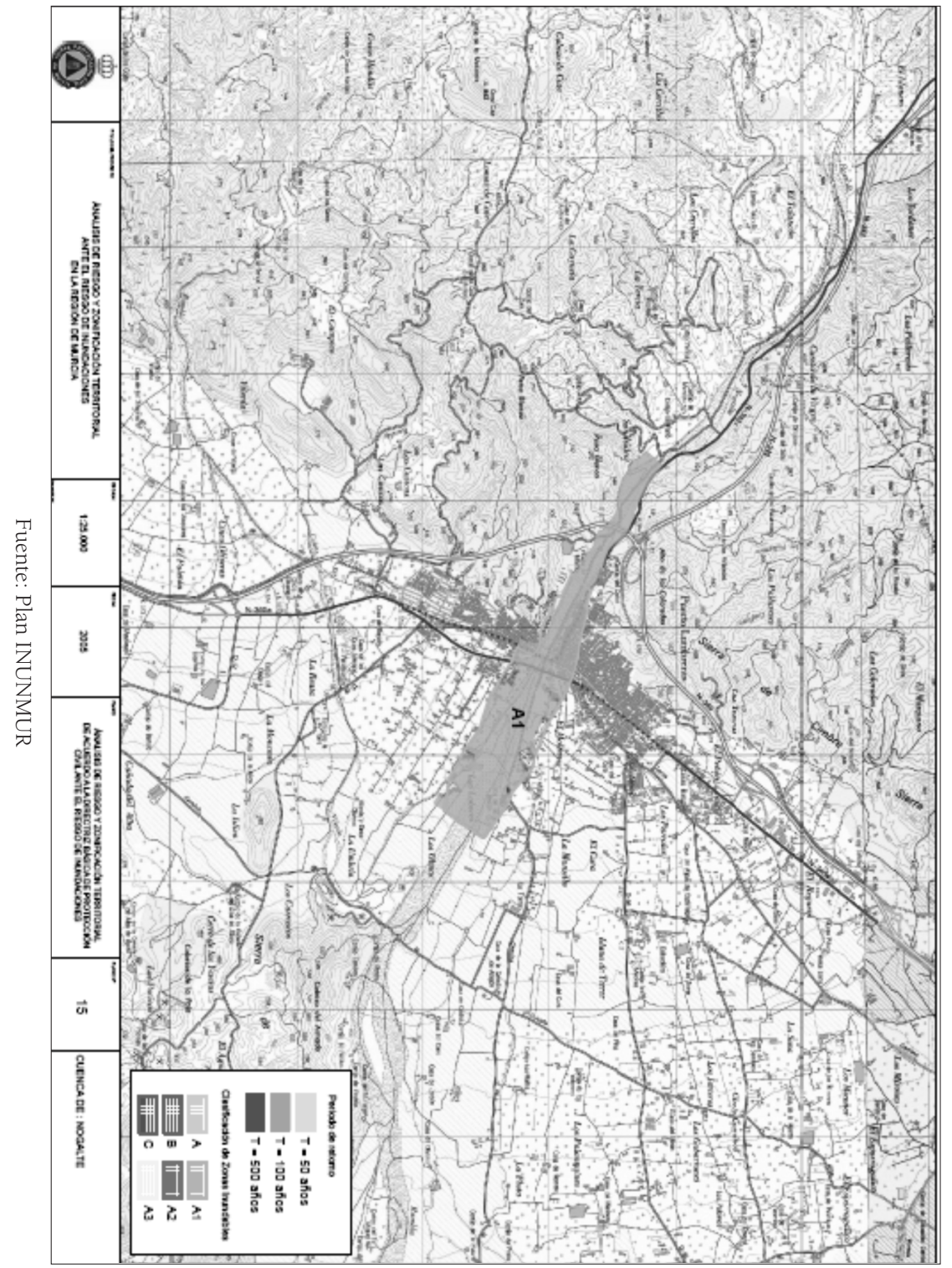

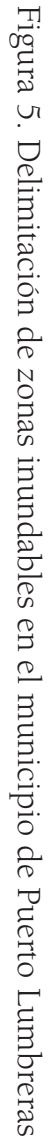


El planificador municipal asume estas recomendaciones y completa la protección de la legislación sectorial mediante la exclusión del proceso urbanizador de ciertos espacios que designa como protegidos por el planeamiento. Según el texto del PGMO:

En ausencia de determinaciones de actuación especificas para estos ámbitos serán de aplicación las asignadas para el suelo no urbanizable protegido por el planeamiento, con grado de protección muy alta, mediante la aplicación de la Ordenanza «A». Excepcionalmente, a los cauces y vías pecuarias se les aplicarán las Ordenanzas "C»" $y \ll D$ ", respectivamente. Y en caso de que existieran, las más restrictivas y las que supongan mayor protección del territorio.

La ordenanza que afecta a los cauces es similar al procedimiento que incluye el PGMO de Lorca, sin embargo, en el caso de Puerto Lumbreras es más restrictiva y emplea la delimitación del dominio público hidráulico y líneas de avenidas extraordinarias para excluir completamente estos territorios del proceso urbanizador.

Según el documento analizado, la delimitación que haya sido efectuada por la Confederación Hidrográfica del Segura prevalecerá sobre cualquiera, con lo cual, se evitan las posibles situaciones de discrecionalidad. En los demás casos, los instrumentos de desarrollo urbanístico del presente PGMO, previamente a cualquier actuación, deberán formular la correspondiente propuesta de delimitación del dominio público hidráulico ante la Confederación Hidrográfica del Segura. Esta propuesta de delimitación, o línea de probable deslinde, debe ser razonada y ajustada en lo previsto en el reglamento del dominio publico hidráulico, la cual se plasma en los planos del instrumento urbanístico junto con la delimitación de las correspondientes zonas de servidumbre y policía. Incluso, si se estima necesario, la propuesta de delimitación se sometería a información pública. Por lo tanto, el planeamiento hace extensible la delimitación propuesta por Protección Civil a cualquier ámbito que sea incluido en algún instrumento de ordenación y que interceda con zonas supuestamente inundables.

En definitiva, se trata de realizar las tareas de deslinde de las zonas del dominio público hidráulico y de la zona inundable de los 100 y 500 años. El procedimiento a seguir es aproximadamente el mismo que viene recogido en los artículos 240, 241 y 242 del reglamento de dominio público hidráulico (según la nueva redacción en la reforma del reglamento aprobada por real decreto 606/2003, de 23 de mayo). De esta manera, el Ministerio de Medio Ambiente, a través del organismo de cuenca, delega dicha tarea (que en principio debía ser realizada a través del proyecto LINDE), sobre el organismo municipal que solicite esa posible transformación, y tan sólo será la confederación la responsable de la aprobación de cualquier propuesta de deslinde del demanio. 
Por otro lado, el PGMO del municipio de Puerto Lumbreras considera este espacio como parte activa en el proceso de ordenación y establece al efecto normas adicionales para la protección de los cauces y terrenos aledaños, en aras de evitar la concurrencia de riesgos naturales. Se trata básicamente de prohibiciones y limitaciones que el documento resume en dos epígrafes:

a: En las franjas de las márgenes delimitadas por la «vía de intenso desagüe» (simplificadamente y del lado de la seguridad, el cauce de avenidas extraordinarias correspondiente a la de 100 años de periodo de retorno)», se prohíben los usos residenciales, siendo los únicos usos permitidos aquéllos que no obstruyan el flujo de avenidas y no requieran estructuras, terraplenes o almacenamiento permanente de bienes y equipos, y que no afecten desfavorablemente a la capacidad de dicha vía de intenso desagüe.

$b$ : En la zona inundable (su límite se establece reglamentariamente por los niveles teóricos que alcanzarían las aguas en las avenidas de 500 años de periodo de retorno) que se caracterice como "zona de inundación peligrosa» (velocidad $>1$ $\mathrm{m} / \mathrm{seg}$, calado $>1 \mathrm{~m}$, o velocidad por calado $>0,5)$, también se prohíben los usos residenciales.

c: En el resto de la zona inundable que no tenga consideración de zona de inundación peligrosa, los usos quedarán condicionados, en cada caso, a los daños potenciales que se pudieran producir.

Sin perjuicio del contenido concreto de la ordenanza, los usos permitidos en los suelos no urbanizables protegidos por el planeamiento e inadecuados para el desarrollo urbano, son por lo general de escaso impacto sobre el territorio, por lo que se deduce que no representarían un obstáculo a la libre circulación de las aguas de escorrentía en aquellos casos que fueran situados sobre espacios inundables. Sin embargo, hay que señalar que entre ellos existen tres calificados como compatibles, sujetos a autorización de uso excepcional como interés público, que serían: usos turísticos, deportivos o de acampada; edificaciones y usos provisionales los cuales generan cierta preocupación desde el punto de vista de los riesgos de inundación, pues podrían aumentar la exposición al peligro. Aunque de acuerdo a la citada ordenanza, tan sólo podrían instalarse fuera del espacio delimitado por el límite establecido por la avenida de los 500 años de periodo de retorno. Con lo cual, dichas actuaciones, supuestamente, no frenarán el paso del agua cuando se produzca un chubasco de fuerte intensidad horaria que haga funcionar los cauces del municipio.

A pesar de lo positivo del espíritu de la normativa, ésta demuestra ciertas debilidades. Por un lado, el deslinde del dominio público hidráulico se sustenta en una escasa vocación geográfica, que se plasma sobre una cartografía a escala demasiado generalista. Son muchas las variaciones que habrían de llevarse a 
cabo con la finalidad de incorporar la percepción del riesgo de avenidas e inundaciones a la gestión del demanio. Así mismo, los resultados de los periodos de retorno, según autores (OLCINA CANTOS, J. 2007), distan muchas veces de la realidad, pues sus cálculos se basan en series de datos poco fiables. Pese a ello, el procedimiento de deslinde que se defiende desde el PGMO de Puerto Lumbreras es el más restrictivo y excluyente de todos los analizados. La consideración del peligro de inundación y avenida es un condicionante que adquiere suma importancia en dicho planeamiento, y trata de abordarse de forma específica, distanciando cualquier uso del suelo diferente al no urbanizable lejos de los espacios inundables.

No resulta azaroso que esto suceda en Puerto Lumbreras. Como bien es sabido, los episodios de lluvias torrenciales se han cebado con especial violencia en este municipio basta recordar como fecha más significativa la de 19 de octubre de 1973. Además, las medidas estructurales ejecutadas tras la tragedia se demoraron más de 16 años, y son ineficaces para laminar la violencia de las aguas en crecida, pues apenas se realizó una canalización de la rambla a su paso por la población. El sentimiento de desprotección está latente y es más fuerte que en ciudades vecinas como Lorca, donde las actuaciones de control de caudales sobre el Guadalentín han generado en la población una sensación de seguridad que está siendo malinterpretada, provocando la expansión de los espacios afectados por el riesgo natural de inundación.

\section{CONCLUSIÓN. EL FRACASO DE LAS ORDENANZAS MUNICIPALES EN LA PREVENCIÓN DE INUNDACIÓN.}

Los planes generales de ordenación urbana son documentos jurídicos suficientemente capacitados para integrar en la ordenación municipal los potenciales riesgos naturales que puedan estar presentes en un territorio concreto. Sin embargo, el análisis pormenorizado de los casos, demuestra, al menos en los casos consultados, como dichos trabajos insertan los riesgos naturales como un añadido ajeno al proceso de asignación de usos, que tan sólo interviene como un factor limitante, y en absoluto, como parte integrante del medio en el que se pretende gestionar el crecimiento urbano.

Los espacios afectados por riesgos de cualquier índole se incluyen en la categoría de suelo no urbanizable. Para su ordenación, los planes municipales transcriben lo dispuesto en los artículos $9.1^{\text {a }}$ de la ley estatal de 1998 y art.65.1 de la ley regional 1/2001. En consecuencia, el planeamiento sectorial es el responsable de delimitar el espacio afectado por los posibles excesos de agua que posteriormente el legislador incluirá en el suelo no urbanizable. Para los planes generales de ordenación urbana de los municipios de la Región de Murcia, el documento 
de referencia en la actualidad es el plan INUNMUR elaborado por el organismo de Protección Civil regional.

Los PGMO's analizados regulan también la protección que se hace de los espacios incluidos en la categoría de suelo no urbanizable con medidas propias, unas veces independientes y otras complementarias a las que se hagan desde la legislación sectorial. Como ejemplo de las primeras, los dos municipios del litoral (Águilas y Mazarrón), aplican el art. 22 de la normativa de las directrices y plan de ordenación del litoral, de dudosa fiabilidad en cuanto a la seguridad que ofrecen frente al riesgo de riadas; y en ocasiones solapada con la de Protección Civil, no existe una sinergia entre ambas, lo que podría contribuir a cierta confusión y cometer errores en la planificación. Por su parte, Lorca y Puerto Lumbreras han desarrollado iniciativas propias complementarias al proceso de deslinde del dominio público hidráulico. Pese al refuerzo que supone para la protección de cauces, representan tan sólo un mero formalismo administrativo que limita el uso espacios públicos; no existen en absoluto pretensiones para la mitigación del riesgo en dichas medidas.

Se trata, en definitiva, de una magnífica oportunidad desperdiciada por los legisladores municipales, los cuales, haciendo uso de sus títulos competenciales en ordenación territorial, podrían haber ejercido una valiosa labor por integrar esa política con el medioambiente de sus términos. Un acercamiento bien entendido en ambas materias, se habría materializado en una planificación sensata y adaptada a un medio físico peculiar que ofrece valiosos recursos, pero también, retos complejos que deberían ser considerados como una parte interactiva con las actividades socioeconómicas. Desafortunadamente, la gestión de forma sectorializada de cada una de las variables que configuran el espacio vivido, impide advertir los problemas que comportan los procesos de ocupación si no se contemplan los factores que rigen el medio físico.

Pese a todo lo anteriormente expuesto, comienzan a divisarse nuevas luces en el tratamiento del riesgo de inundación dentro de los procesos de ordenación. Por un lado, la ley 8/2007, de 28 de mayo, de suelo estatal, contempla por primera vez el concepto de riesgo de inundación. De hecho, resulta llamativo el hincapié que se hace en el mismo (art.12), pues es el único que se distingue del grupo de los riesgos naturales que afectan al territorio español. Además, en virtud del art. 15 de la citada ley, se obliga a los legisladores municipales a incluir un mapa de riesgos naturales del ámbito objeto de ordenación.

Aunque no se precisa ni el método ni la autoría de esos mapas, el redactor del mencionado documento legal parecía ser consciente de la inminente aprobación de una directiva europea sobre la evaluación y gestión de las inundaciones (Directiva 2007/60/CE del Parlamento Europeo y del Consejo, de 23 de octubre 
de 2007, relativa a la evaluación y gestión de los riesgos de inundación), cuya transposición al derecho español debe realizarse antes del 26 de noviembre de 2009. En efecto, en virtud de la misma, los organismos de cuenca, iniciaran la elaboración del Sistema Nacional de Cartografía de Zonas Inundables, cuyo objetivo es aportar una información a tener en cuenta por las administraciones competentes en materia de ordenación del territorio, planificación urbanística y protección civil. Para la cuenca del Segura, el Ministerio de Medio Ambiente y Medio Rural y Marino ha licitado por más de tres millones de euros dichos trabajos y se estima que se tendrán que delimitar 1.250 kilómetros de cauces, lo que se traducirá en un total de 100.000 hectáreas cartografiadas (La Verdad, 14-02-2009). Si se completan los pasos establecidos en este nuevo proyecto, parece que se dispondrá de una cartografía eficiente y lo suficientemente fiable para poder establecer por primera vez una delimitación de las zonas sensibles de sufrir inundaciones acorde con lo que sucede en la naturaleza.

Parece ser que la preocupación por estos condicionantes del medio físico ha cobrado la suficiente importancia en estos últimos decenios como para ser incluido dentro de los procesos de exclusión de suelo urbano. Por tanto, tan sólo queda confiar en que los futuros planes de ordenación municipal y las revisiones de los mismos que se aprueben, apliquen con buen criterio las indicaciones que se hagan para cada caso, con el principal objetivo de integrar con todas las garantías de seguridad el riesgo de inundación en el proceso de ordenación territorial.

\section{BIBLIOGRAFÍA}

Diario la Verdad de Murcia, 14-02-2009, Edición Digital, Sección Región.

Dirección General de Protección Civil de la Región de Murcia (2007): Plan Especial de Protección Civil ante el riegos de inundaciones de la Comunidad Autónoma de la Región de Murcia (Plan INUNMUR). Murcia, soporte digital.

Directrices y Plan de Ordenación del Litoral de la Región de Murcia. Memoria, Murcia, Consejería de Turismo y Ordenación del Territorio, 2004.

Farinós Dasí, J. y Romero González, J. (2008): «La gobernanza como método para encararlos nuevos grandes retos territoriales y urbanos», en Boletín de la Asociación de Geógrafos Españoles, no 46, pp 5-9.

García, R. y Gaztelu, L. Proyecto de obras de defensa contra las inundaciones en el Valle del Segura, 1886, 115 p. Edición facsímil, Ministerio de Medio Ambiente, Confederación Hidrográfica del Segura, 2001, p. 195.

GimÉNez FerReR, J. M. (2003): Riesgo de inundación y ordenación urbana en el litoral meridional alicantino. Publicaciones de la Universidad de Alicante, Alicante, 351 pp. 
Ilmo. Ayuntamiento de Águilas e inCOTEC (2005): Plan General Municipal de Ordenación de Águilas.

Ilmo. Ayuntamiento de LorCa y ETT (2001): Plan General Municipal de Ordenación de Lorca.

Ilmo. Ayuntamiento de Mazarrón y PROINTEC (2007): Revisión del Plan General de Ordenación Urbana de Mazarrón.

Ilmo. Ayuntamiento de Puerto Lumbreras (2006): Plan General Municipal de Ordenación de Puerto Lumbreras.

Ley 1/2001, de 24 de abril, del Suelo de la Región de Murcia. BORM n 113, de 17 de mayo de 2001.

Ley 10/2001, de 5 de julio, del Plan Hidrológico Nacional. BOE, nº 161, de 6 de julio de 2001.

Ley 6/1998 de 13 de noviembre, de Régimen del suelo y valoraciones. BOE, n89, de 14 de abril de 1989.

Ley 8/2007, de 28 de mayo, de suelo. BOE, $n^{\circ} 128$, de 29 de mayo de 2007.

Ministerio de Medio Ambiente (2003): La delimitación del dominio público hidráulico y de sus zonas inundables. El proyecto Linde. Dirección General de Obras Hidráulicas y Calidad de las Aguas, Madrid, 95 pp.

Ministerio de Medio Ambiente, Secretaría de Estado de Aguas y Costas, Dirección General de Obras Hidraúlicas y Calidad de Aguas, Confederación HidrográfiCa del Segura (1997): Plan Hidrológico de la Cuenca del Segura. 2 vols.

Olcina Cantos, J. (2004): Riesgos de inundaciones y ordenación del territorio en la escala local. El papel del planeamiento urbano municipal. Boletin de la Asociación de Geógrafos Españoles, n 37, (monográfico «Agua y Ciudad»), Madrid, Asociación de Geógrafos Españoles, pp. 49-84.

Olcina Cantos, J. (2007): «Ordenación del territorio en la mitigación de riesgos naturales en España», en Riesgos naturales y desarrollo sostenible. Impacto, predicción y mitigación. Ministerio de Educación y Ciencia e Instituto Geológico y Minero de España. Madrid, pp.65-88.

Pérez Morales, A. (2008). Aumento del riesgo de inundación por ocupación indebida de las áreas de convergencia de aguas en el Sur de la Región de Murcia», en Scripta Nova. Revista Electrónica de Geografía y Ciencias Sociales. Barcelona: Universidad de Barcelona, vol. XII, núm. 270 (27). Disponible online: <http://www.ub.es/geocrit/sn/sn-270/sn-270-27.htm> [ISSN: 1138-9788] 